\title{
Considerações sobre o olhar no jornalismo literário
}

\section{Resumo:}

Este artigo tem como objetivo analisar um aspecto recorrente em livros que exploram as fronteiras do jornalismo e da literatura. Trata-se de um duplo gesto em relação ao olhar. Um gesto que, de diferentes maneiras, valoriza o olhar do narrador, mas ao mesmo tempo reconhece suas limitações. Esta declaração simultânea de potência e insuficiência pode ser observada em um amplo espectro de autores das mais diversas procedências, mas aqui proponho examiná-la em três escritoras latino-americanas: a brasileira Eliane Brum e as argentinas Leila Guerriero e Selva Almada.

\section{Palavras-chave:}

Jornalismo literário, olhar, Eliane Brum, Leila Guerriero, Selva Almada

\section{Abstract:}

This article aims to analyze a recurring aspect in books that explore the boundaries of journalism and literature. It is a double gesture regarding the look. A gesture that, in different ways, values the narrator's gaze ("What I saw, nobody could see"), but at the same time recognizes its limitations. This simultaneous declaration of potency and insufficiency can be observed in a wide spectrum of authors from the most diverse origins, but here I propose to examine it in three Latin American writers: the Brazilian Eliane Brum and the Argentine Leila Guerriero and Selva Almada.

Keywords:

Literary journalism, look, Eliane Brum, Leila Guerriero, Selva Almada

A categoria da não ficção se afirma, antes de tudo, por uma negação. Estaria fora dela o que é fictício, o que é inventado, o que é deliberadamente concebido sem fidelidade estrita ao real. Mas seria esse bloqueio efetivo? Sabemos que não. E não apenas pelo caráter parcial de todo discurso, determinado por escolhas, pontos de vista e noções preestabelecidas, mas pela carga imaginária da memória e dos sentidos que damos ao mundo. Mesmo o impulso emergencial 
dos testemunhos, marcados pelo "imperativo da crença" segundo Beatriz Sarlo (2005: 47), não garante a fidedignidade do que é narrado. Dissociar o que ocorreu do que imaginamos ter ocorrido é tantas vezes impossível, diz Paul Ricoeur (2007: 172), citando desde experiências da psicologia judiciária - em que pessoas assistem a uma mesma cena e depois a narram de maneira diferente - ao que Freud denominou "elaboração secundária", uma remodelação da lembrança a fim de torná-la mais coerente e compreensível. A própria "realidade", bem longe de algo absoluto, é uma construção social impregnada de ficções.

Isto impõe desafios árduos para o narrador de não ficção. Abstendo-se da invenção, cabe a ele contar o que ouve, o que vê e o que experimenta, mas ao mesmo tempo reconhecer que o que vemos, ouvimos e experimentamos será sempre insuficiente, seja por desvios intencionais dos informantes, seja pela distância entre o que se vive e o que se conta, um percurso sempre marcado pelos mais diversos condicionantes. Implícita no gesto, há a ruptura com a concepção positivista de verdade, subordinada necessariamente à verificação factual. Em seu lugar, emerge uma verdade interpretativa, "de desvendamento", como propôs Todorov (1991) em oposição à "verdade de adequação", aferível pelo sim e pelo não.

Neste artigo pretendo analisar um aspecto recorrente em livros que exploram as fronteiras entre o jornalismo e a literatura. Trata-se de um duplo gesto em relação ao olhar. Um gesto que, de diferentes maneiras, valoriza o olhar do narrador ("o que vi, ninguém conseguiu ver"), mas ao mesmo tempo reconhece suas limitações ("o que vi não foi o bastante" ou "talvez não tenha sido assim"). Esta declaração simultânea de potência e insuficiência, de argúcia e falibilidade, pode ser observada em um amplo espectro de autores das mais diversas procedências, mas aqui proponho examiná-la em três escritoras latino-americanas: a brasileira Eliane Brum e as argentinas Leila Guerriero e Selva Almada. Minha hipótese é que, longe de um elemento fortuito, essa ambivalência é um ato deliberado, quase um termo de compromisso de quem escreve não ficção ciente das armadilhas que há no gênero.

Começando por Eliane Brum, é interessante notar a centralidade que o olhar ocupa já no título de seus primeiros livros, sobretudo no segundo, A vida que ninguém vê (2006), e no terceiro, 0 olho da rua (2008). Composto de 23 textos publicados originalmente em uma coluna do jornal Zero Hora, A vida que ninguém vê reúne histórias de pessoas comuns que, na concepção da jornalista, mostram o que há de extraordinário no ordinário da existência. Um carregador de malas que sonha em viajar de avião. Um descascador de eucaliptos que, no intervalo de alguns dias, enterra a mulher e a filha em covas rasas. Um colecionador de objetos descartados. Uma senhora tachada de doida por vituperar diariamente contra os vereadores. Essas e outras personagens - retratadas na maior parte das vezes em locais periféricos de Porto Alegre e imediações - seguiriam para sempre inadvertidas se não fosse o olhar sensível e perscrutador da jornalista escritora. É o que nos sugere o título, no qual vemos inevitavelmente um complemento implícito: A vida que ninguém vê... "mas que eu vejo".

Esta valorização do próprio olhar - um olhar capaz de revelar o invisível - prossegue em O olho da rua, coletânea de reportagens publicadas na revista Época na primeira década dos anos 2000. Os cenários e personagens reafirmam a busca do inexplorado, o interesse em se 
voltar àquilo que ninguém mais está olhando. Esse gesto é ressaltado em diversos momentos do livro, em que a presença da repórter em regiões distantes dos grandes centros é contrastada com a indiferença generalizada do restante do país. "Elas nasceram do ventre úmido da Amazônia, do norte extremo do Brasil, do estado ainda desgarrado do noticiário chamado Amapá", começa a matéria sobre as parteiras da Amazônia (Brum 2008: 16, grifo meu). "O Brasil não dá importância a Roraima", diz o texto seguinte (idem: 43), sobre os conflitos e disparidades no estado brasileiro com maior percentual de indígenas. "O Povo do Meio pode desaparecer antes que o país oficial se aperceba dele", afirma, mais adiante, a matéria sobre uma comunidade de pessoas sem documento no interior do Pará (idem: 137). Não basta olhar, é preciso frisar a excepcionalidade do gesto.

Nos pequenos textos publicados ao fim de cada reportagem - nos quais Brum admite erros, aponta acertos e tece considerações sobre o seu trabalho -, o olhar continua no centro dos comentários. É preciso, segundo ela, "ver bem de perto" (idem: 65), "complicar" o olhar (idem: 236), "manter o olhar de espanto" (idem: 259) e, principalmente, "olhar para ver" (idem: 208). Mas a defesa dessas atitudes se dá simultaneamente ao reconhecimento de sua complexidade. Ao examinarmos o título do livro, aliás, notamos uma mudança de perspectiva em relação à obra anterior. Se aquela, como dissemos, nos convida a pensar num complemento implícito para o título (A vida que ninguém vê... "mas que eu vejo"), agora, em 0 olho da rua, um pequeno deslocamento coloca a própria rua na posição de observadora. E a jornalista que observa, por sua vez, passa a ser igualmente observada. Isso nos faz pensar não apenas no autoexame empreendido pela autora, mas nas possibilidades de apreensão de seu olhar. Esta, evidentemente, jamais poderá ser plena. Porque, se é da rua o olho do título, é porque a rua está viva e, estando viva, é mutante por natureza, imune a decifrações cabais e ao toque absoluto do olhar que a busca. "O que vemos só vale - só vive - em nossos olhos pelo que nos olha. Inelutável porém é a cisão que separa dentro de nós o que vemos daquilo que nos olha", diz Georges Didi-Huberman (2010: 29) em um ensaio que se presta a um diálogo profícuo com a inversão de perspectivas operada pelos títulos de Brum.

Na prática, a intenção declarada por ela de "desabitar-se de si para habitar o outro" (Brum 2008: 364) resulta por vezes fracassada, como admite ao analisar a reportagem "A casa de velhos", fruto de uma imersão de uma semana em um asilo no Rio de Janeiro. "Eu não os poupei. Não os protegi. Falhei", reconhece a escritora ao contar o desconforto que a publicação da reportagem provocou no asilo (idem: 112).

Eu os tratei como personagens de ficção, não como gente real. Eles se ouviram falando de sonhos eróticos, de ardores noturnos, de confinamento. E tiveram de viver com isso, encontrando-se no dia seguinte pelos corredores da Casa (idem: 112).

Há ainda outras admissões de falha, ou insuficiência, de um olhar que, em outros momentos, afirma-se poderoso em contraposição à miopia generalizada. Brum relata que, na reportagem sobre Roraima, não soube ver propriamente os Yanomami, tratados com superficialidade 
Cadernos de Literatura Comparada

Considerações sobre o olhar no jornalismo literário

e sem a contextualização necessária. Penitencia-se também a respeito do texto anterior, por não ter acompanhado um parto feito pela parteira mais velha do Amapá, trocado por uma entrevista que havia agendado com uma governadora. No posfácio da obra, a própria transcrição da palavra oral para a escrita é apontada como um problema, por reproduzir a violência de que são vítimas as populações mais pobres, como os ribeirinhos que lhe serviram de fonte em muitas reportagens sobre a Amazônia.

Não tinha convicção de que era ético converter em letra a palavra oral que pertencia a um outro - e a um outro que era persistentemente violado pela palavra escrita. Temia que o que eu nomeava como encontro pudesse ser violência. E o que eu chamava de reportagem fosse grilagem de almas. (Brum 2008: 367)

\section{0 reino do olhar}

Uma das maiores referências contemporâneas no jornalismo literário em língua espanhola, Leila Guerriero costuma descrever o jornalismo como "o reino do olhar". Uma leitura atenta de seus livros - em especial dos dois que mencionaremos aqui - sugere a busca de uma poética do olhar, considerando a estruturação da narrativa e as reflexões que atravessam o texto. Guerriero aparece sempre em cena, representada primordialmente como observadora. Seu empenho em ver, no entanto, se defronta com a incompletude, as zonas de sombra e as lacunas muitas vezes irremediáveis em suas buscas.

Em Los suicidas del fin del mundo: crónica de un pueblo patagónico, publicado pela primeira vez em 2005, Guerriero viaja à pequena cidade de Las Heras, na província de Santa Cruz, Patagônia, onde 12 pessoas com idade em torno de 25 anos se mataram entre março de 1997 e dezembro de 1999. Já nas primeiras páginas, ela admite a insuficiência de sua pesquisa, ao se referir aos jovens como "um punhado de nomes dos quais não sabia - ainda não sei - nada" (Guerriero 2015: 25). ${ }^{1}$

Indo de família em família, a jornalista busca descobrir as motivações dos suicídios, mas, de modo geral, não encontra explicações convincentes. Muitos dos que se mataram fizeram-no sem dar pista, como um ato aparentemente intempestivo, a exemplo da adolescente que um dia se fechou no quarto e disparou um tiro contra a própria cabeça. Resistindo à ficcionalização comum em obras do gênero - basta pensar no clássico A sangue frio (1967), de Truman Capote -, Guerriero raramente utiliza o discurso indireto, privilegiando a transcrição das declarações e contextualizando o momento em que são feitas. Ou seja, não basta dizer que um personagem contou que seu filho era depressivo, é preciso dizer que a afirmação se deu num dia chuvoso em que o vento atingia com força os vidros da residência. Ao optar por esse procedimento, Guerriero nos lembra, implicitamente, que aquilo que dizemos varia de acordo com as circunstâncias. Um mesmo acontecimento pode ser lembrado de uma forma negativa ou positiva, dependendo do dia em que evocado. Ou, como escreveu Janet Malcolm: "Na vida, nenhuma história é contada duas vezes exatamente da mesma forma. À medida que o barro úmido da 
realidade passa de mão em mão, assume diferentes formas engenhosas" (Malcom 2011: 162).

Saber concretamente os motivos de um suicídio é impossível, e, por isso, a busca de Guerriero tem como horizonte máximo uma "verdade de desvendamento", como citamos anteriormente, em alusão à verdade que não depende de provas materiais. "Os dados dizem, mas nunca explicam", diz ela, enfronhada nas estatísticas de suicídios (Guerriero 2008: 61). Em paralelo às entrevistas com familiares, a autora faz uma investigação sobre a cidade, na qual, desde o início, acentua os elementos lúgubres. A paisagem fria é cortada por um vento constante, que, à noite, golpeia as janelas das casas e instaura uma atmosfera assustadora. As perspectivas dos jovens não inspiram esperança. Movida pela exploração de petróleo a partir de uma unidade da YPF - antiga estatal, privatizada na década de 1990 -, Las Heras não oferece muito mais do que trabalhos precários no decadente setor de serviços. Quem tiver mais ambição - a começar por uma carreira universitária - deve sair da cidade, aonde chegaram, por sua vez, centenas de migrantes atraídos pela prosperidade do petróleo.

Para além do círculo dos suicidas, Guerriero entrevista personagens diversos da cidade: prostitutas, garçons, um cabeleireiro gay que abre as portas de sua casa e mostra sua coleção de pôsteres eróticos. Assim como Eliane Brum, sua curiosidade contrasta com o desinteresse dos grandes centros do país, incluindo os meios de comunicação hegemônicos. "Como será, pensei, não se ver refletido nas notícias, não entrar nunca na previsão do tempo, na estatística, não ter nada a ver com o resto de um país inteiro", pergunta-se diante do noticiário (Guerriero 2008: 149).

A centralidade do olhar é ainda maior em Una historia sencilla [Uma história simples, 2013], livro em que a jornalista acompanha um competidor de um festival de dança folclórica - o malambo - realizado anualmente na pequena cidade de Laborde, na província de Córdoba. "É uma das milhares de cidades do interior cujo nome não soa familiar para o resto dos habitantes do país", afirma Guerriero, destacando a obscuridade do objeto de seu interesse (Guerriero 2013: 10). Desconhecida em nível nacional, Laborde tem, no entanto, um caráter mítico para os praticantes de malambo, recebendo uma peregrinação de dançarinos com suas comitivas de todos os cantos da Argentina e de países vizinhos, como a Bolívia e o Paraguai. Logo no início, ao lembrar o dia em que tomou conhecimento do festival - lendo casualmente o jornal -, Guerriero diz que, desde então, não deixou de pensar. "Em quê? Em ir ver, suponho" (ibidem).

São, a partir disso, numerosas e significativas as aparições do verbo ver, bem como as considerações sobre os desafios de quem, como ela, está ali para enxergar. Nem "a duração das jornadas - das sete da noite às seis da manhã - nem o que o se vê nelas é apto para olhos que buscam digestão fácil", adverte já nas primeiras páginas (idem: 16).

Em seguida, já em Laborde, Guerriero aparece em cena na condição habitual de observadora: "Estou olhando a copa de uns eucaliptos, que não conseguem deter as garras do sol, quando o escuto. [...] Viro e vejo um homem sobre o palco" (idem: 24). A narrativa segue se desdobrando de descrições precisas, meticulosas, que muitas vezes proliferam a partir de enumerações: 
Cadernos de Literatura Comparada

Considerações sobre o olhar no jornalismo literário

Às oito da noite, as ruas que desembocam no prédio estão fechadas para o trânsito. Dentro do prédio, uma onda de gente caminha pela feira que montam ali e onde se vendem alfajores, doces caseiros, massas secas, cortinas de banheiro, roupa para cachorros, cintos de couro, mate, bijuterias de prata, facas, camisetas. (idem: 26)

Esta visualidade intensa e virtuosística é intercalada por comentários que, em alguma medida, funcionam quase como um caderno de anotações de um observador, registrando obstáculos, progressos e uma série de contingências. Em diferentes momentos, a narradora manifesta a sensação de ver sempre a mesma coisa, como se a identificação do específico tardasse, ofuscada por estereótipos e pelos clichês encarnados pelos objetos de seu olhar. O que a instiga - ou o que a olha, para lembrar Didi-Huberman - também é tema de reflexões, assim como as ausências por trás do presente, o invisível incrustado no visível. A representação desta alternância - ausência e presença, visibilidade e invisibilidade - é favorecida pelo cenário em que Guerriero se move na cobertura do festival. Separados por uma divisória, o palco e os bastidores são inapreensíveis a uma só visada. É preciso alternar-se entre o dois. Assim, para ver os dançarinos nos camarins, a narradora deve renunciar à visão do palco, e vice-versa. A inevitável perda dos dois ângulos é evidenciada a cada momento para o leitor, que se regozija com a potência mas constata a insuficiência do olhar da narradora.

Este paradoxo do olhar - potente e insuficiente ao mesmo tempo - aparece de diversas formas em Chicas muertas [Garotas mortas], de Selva Almada, publicado pela primeira vez em 2014. A base do livro é a história de três feminicídios, que a escritora relembra, investiga e entrelaça com episódios de sua própria vida, tanto no presente quanto na infância e na adolescência. A figura folclórica da Huesera é usada para representar o propósito do livro: dar voz aos mortos, ressuscitá-los, juntar os ossos, montar o esqueleto e, com o canto, restituir-lhes a vida (Almada 2018: 50).

O livro mistura memórias com reportagem. Propõe-se a contar a história dos feminicídios, mas também o impacto que os assassinatos - sobretudo o primeiro de que tomou conhecimento, o da estudante de psicologia Andrea Danne - tiveram na vida de Almada. Narrado em primeira pessoa, é em parte um retalho de autobiografia, da escritora que cresceu ouvindo histórias de violência contra mulheres, mas também de resistência.

De grande potência descritiva, Chicas muertas é ambientado em territórios afastados dos grandes centros, cidades pequenas assediadas pela pobreza, o conservadorismo, o sexismo e, em alguns casos, a dependência de uma única atividade econômica. Se na Las Heras descrita por Guerriero havia uma subordinação à atividade petrolífera, e particularmente à YPF, em San José o trabalho está vinculado ao frigorífico local e, em Ciudad Sáenz Peña, é fortemente influenciado pelo dono da empresa de ônibus. A paisagem é frequentemente árida, hostil, desolada.

A perseverança de Almada, logo se vê, não bastará para que descubra muita coisa sobre os assassinatos. As informações sobre as mortes são permeadas de lacunas e incertezas. Palavras como "talvez" e "aparentemente" se multiplicam. Nem mesmo o corpo atribuído a uma das 
vítimas é comprovadamente dela. Os processos, além disso, registram vários falsos testemunhos: alguns mentem deliberadamente, outros se confundem, são traídos pela memória. E há aqueles que optam pelo silêncio.

Diante disso, ciente da impossibilidade de descobrir as circunstâncias dos assassinatos, Almada recorre a uma vidente, assim como fizeram outras pessoas próximas às vítimas. A figura da vidente, sem dúvida, é a que melhor expressa a insuficiência do olhar da narradora. Uma mulher que incorpora os mortos e enxerga zonas infranqueáveis aos comuns mortais. Para ela, ver significa interpretar as cartas do tarô - supõe, portanto, uma decifração. "Acho que o que precisamos conseguir é reconstruir a maneira como o mundo olhava para elas. Se conseguirmos saber como elas eram olhadas, vamos saber como olhavam para o mundo", diz a vidente, reforçando a duplicidade entre olhar e ser olhado (Almada 2018: 119).

Outro aspecto importante do livro de Almada são suas considerações sobre não ficção, que apontam o caráter ficcional de vários relatos que circularam sobre as mortes, a começar pela cobertura da imprensa, que incorpora versões fantasiosas e logo adquire feições de folhetim policial de má qualidade.

\section{Considerações finais}

As leituras compartilhadas aqui reúnem apenas as considerações iniciais de uma pesquisa sobre o olhar e a escuta no jornalismo literário. A diversidade e a riqueza das questões levantadas reforçam a importância de aprofundar as discussões sobre o tema. Essencial na prática jornalística, o olhar atento e acurado está entre as prescrições obrigatórias para o bom exercício do ofício, mas a complexidade de tal requisito ainda carece de discussões suficientes, seja na academia, seja no mercado. O mesmo se pode dizer de imperativos como "tirar da invisibilidade" e "dar voz aos silenciados", que circulam como clichês, sem contar necessariamente com uma compreensão sobre os desafios dos dois propósitos.

\section{NOTAS}

* Diogo de Hollanda é graduado em Jornalismo pela Universidade Federal Fluminense (UFF), com mestrado e doutorado em Literaturas Hispânicas pela Universidade Federal do Rio de Janeiro (UFRJ). Foi professor de Literaturas Hispano-Americanas da UFRJ (2013-2014) e, desde 2017, é professor de Jornalismo da PUC-SP. Organizou a reedição dos clássicos O cemitério dos vivos, de Lima Barreto, e Um passeio pela cidade do Rio de Janeiro, de Joaquim Manoel de Macedo, além de ter traduzido várias obras do espanhol, entre elas os romances La cola de la serpiente, de Leonardo Padura, e Perla, de Roberto Videla. Como repórter, trabalhou nos jornais Valor Econômico, o Globo, Gazeta Mercantil e Jornal do Commercio, e colaborou como freelancer para diversos outros veículos, como Folha de S. Paulo, Reuters, Conjuntura Econômica, revista Pessoa e rádio El espectador, do Uruguai

${ }^{1}$ Todas as citações de Guerriero e Almada foram traduzidas por mim. 


\section{Bibliografia}

Almada, Selva (2018), Chicas muertas, Buenos Aires, Literatura Random House.

Brum, Eliane (2006), A vida que ninguém vê, Porto Alegre, Arquipélago Editorial.

-- (2008), O olho da rua: uma repórter em busca da literatura da vida real, São Paulo, Editora Globo.

Didi-Huberman, Georges (2010), O que vemos, o que nos olha, tradução de Paulo Neves, São Paulo, Editora 34.

Guerriero, Leila (2005), Los suicidas del fin del mundo: crónica de un pueblo patagónico, Buenos Aires, Tusquets Editora.

- - (2013), Una historia sencilla, Barcelona, Anagrama.

Malcolm, Janet (2011), Anatomia de um julgamento: Ifigênia em Forest Hills, tradução de Pedro Maia Soares, São Paulo, Companhia das Letras.

Ricoeur, Paul (2007), A memória, a história, o esquecimento, tradução de Alain François et al, Campinas, Editora da Unicamp.

Sarlo, Beatriz (2005), Tiempo pasado: cultura de la memoria y giro subjetivo. Una discusión, Buenos Aires, Siglo XXI.

Todorov, Tzvetan (1991), As morais da história, Lisboa, Publicações Europa-América. 